I Universidade Federal do Rio de Janeiro (UFRJ),

Escola de Comunicação, Rio de Janeiro, RJ, Brasil

edilson.pereira@eco.ufrj.br

https://orcid.org/o0oo-000I-8308-66IX

Edilson Pereira'

\title{
AS IMAGENS ENCARNADAS ENTRE MORTOS E VIVOS: NOTAS ETNOGRÁFICAS SOBRE RITUAL E RETRATO
}

\author{
"A Foto é como um teatro primitivo, \\ como um Quadro Vivo, a figuração da face imóvel \\ e pintada sob a qual vemos os mortos" \\ R. Barthes (I984: 54)
}

\section{INTRODUÇÃO}

Abordo neste texto a atividade de vestir pessoas vivas e mortas como santos e outros personagens da tradição cristã, um tipo de prática que interliga a(s) pessoa(s) que mimetiza(m) a aparência de uma figura sacra, aquelas que a contemplam e/ou auxiliam em sua atuação e, ainda, a alteridade divina que é focalizada. Partirei da análise desses três vetores relacionais, observados a partir dos dados de minha pesquisa de campo no interior de Minas Gerais, para colocar em questão o uso da fotografia como parte do investimento analítico sobre atividades rituais que se valem da aparência e fisicalidade humanas para representar e atualizar imagens religiosas.

Para tanto, apresentarei a história de morte e vida de uma moradora de Ouro Preto que nos permitirá reconhecer os códigos pertinentes à interpretação de uma iconografia católica e à sua atualização em contextos rituais como a Semana Santa. Ao evocar esta última celebração, uma das grandes festas cíclicas da cidade mineira, descrevo a conjuntura que orienta a produção e atuação de parte de seus principais personagens, a saber: uma centena de pessoas, homens e mulheres de todas as faixas etárias, que se vestem como figuras bíblicas e participam das procissões da época. A descrição da abordagem mantida em relação a tais figuras, sua estética e performance nos conduzirão por conseguinte à reflexão sobre a produção de fotografias mantida durante a pesquisa. Dado que a representação de personae sacras observada em Ouro Preto 
visa capturar a atenção e mobilizar os afetos de seus espectadores e atores, reflito sobre as implicações do uso da fotografia na pesquisa etnográfica a respeito desse tipo de atividade ritual. Complementarmente, apresento uma série de retratos que busca não somente documentar o que foi visto em campo, mas se impregnar pelas formas de expressão nativas e pela atuação engendrada por seus performers, incluindo a mim mesmo (enquanto pesquisador) e os leitores deste texto como parte de seu público potencial.

\section{EXEMPLARIDADE E CÓDIGOS DE VISUALIDADE: COMO CRIAR E DECIFRAR IMAGENS}

A primeira vez que vi uma pessoa vestida como santo católico foi no enterro de minha avó materna. Sob os cuidados de sua filha primogênita, minha tia, seu corpo foi encoberto por uma roupa semelhante à de santa Terezinha, de quem era devota. ${ }^{\mathrm{I}}$ Para acompanhar o cortejo até o sepultamento, minha tia também se vestiu de maneira a mimetizar o traje da santa. Passadas algumas décadas, lidei recentemente com a notícia do falecimento de uma das interlocutoras mais importantes da minha pesquisa a respeito da celebração da Semana Santa em Ouro Preto. ${ }^{2}$ Dona Maria da Conceição Rodrigues, que tinha cerca de 75 anos de idade quando nos conhecemos, em 20I I, era integrante da Ordem Terceira do Carmo, uma versão leiga da mesma ordem religiosa da qual fizera parte santa Terezinha. Ao saber que o hábito da freira carmelita serviu de modelo para a vestimenta de seu último momento entre os vivos, fui tomado pela "lembrança de uma perturbação" (Leiris, 20I7: I5) relacionada à pregnância de certas imagens e de como estas se valem das pessoas, ou da memória que temos delas, para continuar a agir.

As expressões de religiosidade como as que se inferem dos funerais dedicados a essas duas mulheres, entre muitos outros devotos, mostram que no sepultamento não há só um corpo sem vida, mas a sobreposição entre a imagem do falecido e a de uma alteridade divina, que se torna copresente - potencialmente afetando o primeiro. ${ }^{3} \mathrm{Em}$ minha pesquisa de doutorado (Pereira, 20I4) e em desdobramentos posteriores (Pereira, 20I5; 20I6; 20I7), o tema da morte é abordado a partir do estudo da Semana Santa, época caracterizada pela ritualização coletiva do luto vinculado à Paixão de Cristo. Trata-se de um tempo de rememoração da passagem entre vida-morte-ressurreição do filho de Deus tornado homem, que, em cidades como Ouro Preto, se caracteriza pela celebração de missas, procissões, encenações e outras práticas devocionais que, em conjunto, exprimem diversos usos e modos de relação estabelecidos com as imagens religiosas. Nos últimos anos, analisei em detalhe as tensões sociais e múltiplas motivações que a festa engendra, bem como a biografia cultural e a pragmática ritual relacionada às efígies e atores humanos que personificam o papel do protagonista da festa, o Cristo. Neste relato de pesquisa, complementarmente, concentrarei minha atenção nos demais personagens que compõem, ano após ano, as principais procissões da festa. 


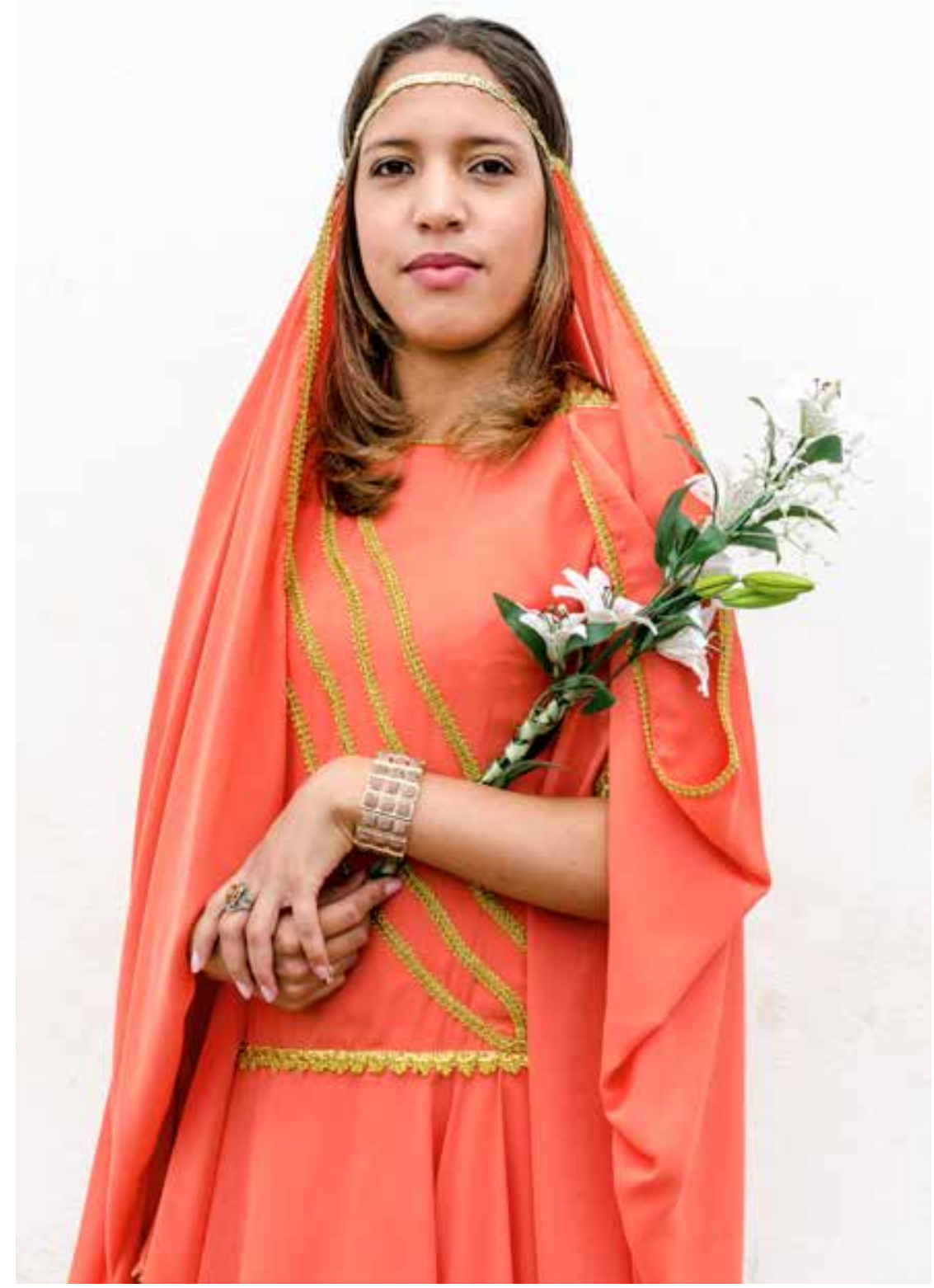

\section{Série Figurados}

Nádia Aparecida de Paula como Virgem. Na iconografia

católica, o lírio branco indica pureza e castidade,

repetindo-se em figuras como São José, o esposo de Maria

Ouro Preto, 20I5. Acervo do autor 
Para abordar essas outras figuras, gostaria de retomar a história daquela senhora ouro-pretana, dona Maria da Conceição, para observá-la além do momento de sua morte. Comentarei alguns eventos importantes que compuseram sua história de vida e que nos permitem observar pontos de continuidade entre, de uma parte, certas referências iconográficas do catolicismo que excedem as situações rituais e se transformam em um tipo de sagrado diluído na vida cotidiana (Leiris, 20I7) e, de outra, as formas de expressão estética implicadas em artefatos e performances como as da Semana Santa.

Em uma de nossas conversas, dona Maria relatou um episódio ocorrido ainda em sua juventude e que se manteve gravado na memória. Quando "moça", dizia, ela cultivava um profundo desejo de se tornar freira. Sonho que, todavia, teria sido frustrado pelo pai, contrário à sua ida para o convento. Depois de vê-la sofrer pela negativa paterna, tomada como inquestionável, sua mãe se teria compadecido e encontrado uma solução alternativa para a situação. Se não era possível seguir o exemplo de Teresa de Lisieux, que já inspirava a filha, elas então se valeriam da imagem da santa para sobrepô-la à sua própria. Maria se vestiria como a jovem santa (falecida aos 24 anos de idade). E o momento escolhido para a mimetização foi justamente o domingo de Páscoa, época na qual muitas imagens e importantes narrativas do cristianismo vêm à tona.

Embora esse episódio tivesse ocorrido há mais de 60 anos e dona Maria lamentasse não ter nenhum registro fotográfico daquela experiência, "eu tenho só na memória”, ela era capaz de narrar a preparação de sua atuação elencando os seguintes detalhes:

[Minha mãe] mandou comprar as fazendas e mandou fazer uma sandália pra mim, bonita. Santa Terezinha usa um... cinto preto com rosário ao lado da túnica. É... embaixo do escapulário. Então, tudo isso [ela] mandou fazer. O sapateiro da rua, chamava Seu Fortunato [...], fez a correia pra mim, a sandália, né? [...] Veja que beleza. Eu vesti aquela roupa marrom linda. Que era um tecido um pouco cintilante. Não muito cetim, mas era uma fazenda bonita, chamava cetim royal, na época. Cetim royal. Não era brilhante não. E... minha tia, irmã da mamãe, fez a minha roupa.

E eu fui num asilo pedir à irmã [freira] [...] a capa dela, pra minha tia tirar o modelo [de costura]. Que santa Terezinha usa uma gola em volta do pescoço, né? Apresentando apenas o rosto dela. Só aparecia o rosto. E eu fui lá no asilo buscar. A irmã me emprestou a capa dela... a gola que colocava em volta do rosto de santa Terezinha. Aí, minha tia fez direitinho. Branca... assim.

Eu fiquei igualzinha a santa Terezinha. Muito linda.

Com o apoio materno, Maria se apresentava publicamente como a santa e se tornava "muito linda" - expressão qualificativa que ela também usava, na época de nossas conversas, para se referir às santas e aos santos de devoção que mantinha em sua própria casa. Entre elas, recordo-me de uma imagem impressa e colorida de santa Terezinha, com cerca de $10 \mathrm{x} 5 \mathrm{~cm}$, que ficava numa 
estante de sua sala, integrando a decoração do ambiente junto com porta-retratos de familiares e vários arranjos de flores. As flores, aliás, compunham parte fundamental não só de sua rotina - pois ela se incumbia da responsabilidade de auxiliar na preparação dos altares da igreja mais próxima de sua casa, antes das missas -, mas igualmente nos reconecta com a iconografia mais difundida de sua santa de predileção.

Em uma das entrevistas que realizamos, dona Maria segurava aquele retrato e me introduzia na biografia da santa, dizendo: "Era ela quem cuidava do jardim em Lisieux, no convento... Ela cuidava das rosas. E diz uma lenda, eu não sei, que ela... espetava a mão com o espinho. Então, ela entregava a Jesus aquele martírio [...] aquele sacrifício". As reproduções que retratam a santa costumam apresentá-la vestida com um hábito marrom e bege, com uma capa mais escura sobre a cabeça, carregando um crucifixo quase todo coberto de rosas. As cores da roupa permitiriam inferir seu pertencimento a uma ordem religiosa específica, enquanto as rosas com o crucifixo conectam-se com o espaço no qual ela viveu e se santificou. A etimologia de "Carmelo" - nome originariamente usado para se referir a um monte na Terra Santa - remete a "jardim", e foi no convento em Lisieux que se manifestaram alguns sinais de sua santidade. As rosas, com seus espinhos, exprimem uma das formas de martírio que a singularizaram e que reforçam um ideal de exemplaridade positiva comum ao simbolismo católico. Ela oferecia aquele sofrimento para Jesus que, por sua vez, seria o "santo dos santos", imagem prototípica e exemplar da qual todos os demais seriam emulações (Jolles, I976). Em uma única imagem, como aquela mantida na casa da senhora ouro-pretana, condensa-se um conjunto de signos e informações vinculadas à hagiografia da figura que ela havia mimetizado quando jovem.

"Um santo é uma combinação interessante de história e estória, agregando regimes distintos de verdade que entram em jogo em seu culto", relembra Menezes (20I I: 50). E as suas imagens, complementarmente, exibem os elementos distintivos que, por um lado, permitiriam identificá-lo dentro do panteão católico e, por outro, remetem a artefatos, lugares ou eventos que compõem a narrativa mais difundida ou legitimada de sua exemplaridade. Assim, seja sob a forma de estátuas, pinturas ou de impressões gráficas produzidas em escala industrial, a imagem dos santos e personagens católicos costuma ser reproduzida segundo uma estética particular, um modelo que frequentemente articula "um conjunto de símbolos, como numa linguagem religiosa que se adquire através de certa 'socialização' e que envolve a habilidade de manipulação de uma série de códigos” (Menezes, 20I I: 5I).

Tal socialização pode marcar a biografia das pessoas que, depois de mortas, serão incluídas no rol de santos. Thérèse de Lisieux, por exemplo, manifestava publicamente sua admiração por santa Joana d'Arc, personagem que chegou a encenar em dada ocasião, vestindo-se e fazendo poses que seriam 
similares à da mártir medieval. A devota francesa, que chegou a ser fotografada como a personagem que a precedia em séculos, afirmava: "a história das façanhas de Joana d'Arc me encantou. Senti em meu coração o desejo e a coragem de imitá-la" (tradução livre)4. Duplo princípio de imitação, portanto, com os santos (representados em diversas mídias, incluindo o corpo humano) inspirando pessoas vivas a copiá-los espiritual e materialmente, gerando uma continuidade de reproduções criativas que atravessam o tempo e demandam saberes específicos.

Quando se observa a história de dona Maria, nota-se que foi preciso acionar uma série de conhecimentos e técnicas - como a modelagem de sapatos, de roupa e a decodificação da imagem sacra - para viabilizar a atuação como uma santa, bem como permitir aos demais reconheer aquela mesma figura. A senhora ouro-pretana considerava que estava "muito linda" e que "parecia uma santinha" porque esses eram, dizia-me, os elogios que havia recebido na ocasião por parte de seus contemporâneos que participavam da procissão citada anteriormente. Ou seja, tal forma de reproduzir a imagem de uma figura cristã articula-se também, e inextrincavelmente, à existência de certo público espectador, seja ele composto por familiares e vizinhos ou, ainda, por turistas e pessoas que não têm necessariamente algum repertório prévio sobre a figura encenada. Esse é um ponto importante sobre o qual voltarei adiante.

\section{OUTROS PERSONAGENS E SUA APARÊNCIA}

Ao longo de sua vida, dona Maria se vestiu como outros personagens do panteão católico, além de sua santa preferida. Entre eles, ela encarnou a Verônica, figura acionada nas encenações, pinturas e narrativas que recontam os principais eventos da Paixão de Cristo. Verônica, ou vero ícone, é o nome utilizado para designar tanto a mulher que acompanhava o sofrimento de Jesus a caminho do Calvário e que, por compaixão, limpou seu rosto ensanguentado quanto o próprio tecido (o sudário) no qual, após o contato com o rosto de Cristo, foi reproduzida sua imagem em positivo, como em um retrato - razão pela qual ela é conhecida, no universo do catolicismo, como "padroeira dos fotógrafos". Em Ouro Preto, a atuação pública da Verônica anuncia a chegada da Semana Santa, tempo liminar do cristianismo, e a preparação de uma centena de outras figuras da tradição bíblica que também participam das procissões da época. Nesse momento, um conjunto de personagens do Antigo e do Novo Testamento é selecionado para servir de base à composição do "figurado bíblico", um grupo efêmero composto por crianças, jovens e adultos, homens e mulheres, de diferentes estratos sociais, bairros de origem e níveis de escolaridade que se voluntariam e/ou são convidados pelas "organizadoras" do coletivo para participar da festa. De modo geral, os ex-participantes da atividade são os principais incentivadores da inserção dos novos membros (sejam parentes ou amigos próximos). Muitos deles narram com alegria a sua participação ou a de 
algum familiar na atividade - cujas razões de acontecer podem envolver tanto a devoção religiosa quanto a ideia de que celebração da Semana Santa, para além da religião, seria um dos marcos da "cultura ouro-pretana", como uma festa "da cidade" (Pereira, 20I4).

Embora não haja uma história consolidada a respeito do início da atividade da figuração bíblica em Ouro Preto, podendo remontar ao início do século XX (Campos, 2005), foi principalmente a partir dos anos I970 e I980 que o número de personagens começou a aumentar até chegar ao atual, com mais de cem pessoas. Nessa época surgiram algumas das primeiras políticas locais voltadas para o turismo relacionado às festas populares, além daquele pautado pelos personagens históricos, como Aleijadinho e Tiradentes, e pela arquitetura colonial (Soutto Mayor, 20I2). Sob uma perspectiva mais ampla, foi também nesse período que se iniciou no país uma progressiva valorização do chamado patrimônio imaterial, que se consolidaria posteriormente em políticas de âmbito estadual e federal (Cavalcanti \& Gonçalves, 20I0). Nas últimas décadas, a celebração da Semana Santa em Ouro Preto se tornou um dos pontos altos do calendário festivo divulgado anualmente pela Prefeitura Municipal em sites e editorias de turismo.

Nessa conjuntura, o incremento dos personagens bíblicos nas procissões adicionou-lhes um elemento estético e narrativo, gerando, por um lado, maior visibilidade da festa, sendo um atrativo para turistas interessados em conhecer os "cortejos de tradições centenárias" da cidade mineira. ${ }^{6}$ Por outro lado, cabe ressaltar que parte importante das "tradições" citadas não se vincula necessariamente a um fator externo aos moradores. Em realidade, um estímulo central à produção, ano após ano, do figurado bíblico refere-se a uma rixa mantida entre as duas paróquias centrais - Antônio Dias e Pilar -, que competem entre si na produção de uma festa sempre "mais bonita" do que aquela feita pelo grupo concorrente.?

Considerando a centralidade das figuras bíblicas na Semana Santa, bem como o apelo visual e o conjunto de técnicas e conhecimentos que elas pressupõem, analisei em detalhe as várias etapas que se sucedem até sua atuação pública (Pereira, 20I4). Durante as incursões em campo, entre 2009 e 20I5, acompanhei as reuniões preparatórias mantidas pelos moradores envolvidos e fui socializado nas referências estéticas que inspiram as costureiras e organizadoras do figurado - incluindo o texto bíblico e outros livros, telenovelas como as produzidas pela Rede Record ou, ainda, filmes de temas "antigos", tais como Ben Hur (I959), Cleópatra (I963) e, evidentemente, A Paixão de Cristo (20I4). A manutenção do contato com essas pessoas e materiais permitiu que, em dado momento da pesquisa, eu fosse convidado a participar do grupo e, com isso, pudesse ter acesso aos bastidores da modelagem do figurino, sua fabricação, provas e ajustes. Parte da pesquisa de campo englobou os ateliês de costura, nos quais pude seguir o figurado bíblico desde sua elaboração primeira até sua 
saída em procissão. Nesse contexto, realizei entrevistas nas quais obtive muitos relatos da participação na atividade em anos anteriores - fossem eles narrados em primeira pessoa ou remetendo à experiência de algum parente, frequentemente mostrando os registros fotográficos da experiência de "assumir a pele" de determinado personagem. A observação do figurado ocorreu, portanto, antes, durante e depois de sua participação na festa.

A atuação de tal grupo resulta da conjugação de uma composição material e estética com uma performance pública. Esses dois aspectos, por sua vez, estão interligados à rivalidade que estimula o contínuo aprimoramento dos figurinos produzidos a cada ano. Uma forma de rixa paroquial que é percebida por vários moradores como disputa semelhante àquela que se associa a escolas de samba. Mais de uma vez, ouvi em campo que a Semana Santa seria como um "Carnaval, só que santo". Ocorre, não obstante, que nem as costureiras responsáveis pela alfaiataria, nem os seus modelos/clientes classificam aquelas roupas como sendo um tipo de "fantasia". Enquanto os artefatos utilizados na festa carnavalesca podem servir para inventar disfarces ou dissimular a identidade do brincalhão, o vestuário produzido para rememorar a Paixão cristã se aproxima mais dos sentidos associados à iconografia e representação dos santos católicos. Assim como nas situações em que crianças e adultos (vivos) vestem-se como determinado santo para pagar uma promessa pessoal ou familiar (Lima, 2006), o figurado atualiza o princípio de que, ao "vestir os corpos", deve-se "revelar as almas" de seus portadores (Teulade, 20 i2: I I I).

No caso do figurado bíblico, o simbolismo associado à roupa de cada figura se complementa com a atenção dedicada ao rosto de cada um dos intérpretes. Ao acompanhar a seleção mantida pelas organizadoras da atividade nas paróquias, notei a existência de um parâmetro compartilhado entre elas segundo o qual o rosto de cada pessoa já permitiria entrever, em alguma medida, a feição de seu personagem. Essa é a razão pela qual o figurado não se valeria de perucas, barbas falsas ou maquiagens que envelheçam ou modifiquem propositadamente a "imagem natural" da pessoa ou que produzam, deliberadamente, um efeito de ficcionalização da similitude. Para interpretar o papel de Moisés (do Antigo Testamento) ou Maria Madalena (do Novo), seleciona-se, no primeiro caso, algum homem mais velho que tenha barba e, no segundo, uma mulher jovem com cabelos longos e escuros.

Ora, sendo o rosto um órgão expressivo por excelência, zona corporal que daria acesso à interioridade de alguém (Simmel, I986), ele assume, na performance do figurado, uma posição complexa. Ele encarna a "força de apelo" (Le Breton, I995: 7) de uma pessoa singular e apresenta, por ocasião da festa, a imagem de uma alteridade divina, narrada em alguma parte das Escrituras. O presente e o ausente se reúnem graças à performance ritual. Tendo isso em vista, sugiro às leitoras e aos leitores que os rostos dos retratos que acompanham este texto nos sirvam como índices das histórias/estórias dos intérpretes e dos 
protótipos que eles encarnam, dupla composição estética complementada por seus figurinos particulares e reproduzida com a mediação do dispositivo fotográfico.

\section{RETRATO COMO MÚTUA CAPTURA ETNOGRÁFICA}

Ao abordar uma festa como a Semana Santa ouro-pretana, precisamos incluir no rol de agentes envolvidos em sua realização aqueles que observam, contemplam e/ou fotografam seus principais performers. Nesse sentido, relembro que ao pesquisar um ritual, também as/os antropólogas/os podem assumir e encenar papéis variados, colaborando em sua realização mesmo que inadvertidamente. Michel Leiris (I989), por exemplo, em sua análise sobre os aspectos teatrais da possessão entre os etíopes do Gondar, assume que chegou a ficcionalizar certos estados de saúde para poder acompanhar os rituais de cura, marcados pela possessão, que de outra forma seriam inacessíveis a ele. Uma vez inserido, porém, ele se dá conta de que se havia colocado frente a frente com outra forma de encenação, na qual sua presença influenciava o tipo de transe que ocorria - levando-o a desconfiar de que, algumas vezes, a performance ritual se convertia em um teatro nativo que reagia à expectativa dos europeus. À dimensão criativa dos rituais de possessão somava-se o fato de que cada espírito zâr incorporado por um "cavalo de santo" se caracterizava por um conjunto de traços típicos, como uma pessoa/personagem singular, reconhecível pelos demais. Cada médium podia incorporar vários desses espíritos, um a cada vez, variando em função das situações específicas nas quais o transe se fazia necessário. Por isso, Leiris considera a variação de papéis um "vestiaire de personalités" à disposição dos médiuns, enfatizando os casos de continuidade e entre o vivido e o encenado em seu campo (Leiris, I989, p. 26). Ao recuperar os diários e escritos etnográficos de Leiris, nos quais se descrevem performances e encontros mantidos durante a missão Dakar-Dijbouti nos anos I930, Irene Albers (2008, p. 286, tradução livre) conclui que:

O trabalho de campo pode, assim, ser visto como um estímulo para que a pessoa possuída e o etnógrafo participem de uma performance teatral. [...] O trabalho de campo, conforme reunido no diário de Leiris, revela-se uma situação em que o etnógrafo e o possuído, a cultura europeia e a africana, encenam a si mesmas uma para a outra.

Da mesma forma, a inserção e uso das imagens na antropologia nos remete a uma história que não se restringiu a assegurar a "verossimilhança" de um estudo etnográfico em relação a uma "realidade" estável, disponível para ser observada e fixada por lentes supostamente neutras (Pinney, I992; MacDougall, 2006). Em verdade, toda pesquisa de campo, se compreendida como uma forma específica de encontro, engloba um jogo que interliga elementos ficcionais e literais, e que repercute na potencial transformação tanto dos pesquisadores quanto de seus interlocutores. Um princípio de compartilhamento que 
se verifica no refinado trabalho de etnoficção produzido por Jean Rouch (2003). Alguns de seus personagens representavam-se a si mesmos graças à relação mantida com o antropólogo-cineasta, enquanto este se deixava impregnar pelas estéticas e poéticas nativas para as recriar em formato audiovisual.

Ao considerarmos, por sua vez, a especificidade da imagem fotográfica e de seu uso social, não podemos escapar do vínculo fundamental estabelecido entre retrato e identidade, entre aparência e representação, que atravessa desde as antigas cartes de visite até as formas atuais de se apresentar socialmente através de selfies, cada qual ensejando modalidades específicas de representação de si e de relação com o outro. Se concordarmos com a ideia de que "o retrato é um modo de injetar subjetividade na imagem de uma pessoa ao criar proximidade entre fisicalidade e imagem, fundindo, ou melhor, confundindo imagem e sua representação" (Gonçalves, 20I6: 24I), podemos entender, consequentemente, que a produção de imagens na antropologia participa invariavelmente dos modos de dramatização que permeiam nossos contextos de pesquisa.

Ao nos aproximar de uma cultura religiosa que enfatiza a importância e o poder das imagens como mediadoras de um tipo de presença ou ação divina, como no caso exemplar do culto aos santos, precisamos reconhecer que as fotografias e os vídeos elaborados durante uma pesquisa de campo produzem conhecimento etnográfico uma vez que se relacionem com as formas de expressão cultural que as antecedem e justificam. Isto é, como parte de um empreendimento compreensivo que se deixa afetar deliberadamente pelas visualidades nativas, incluindo aquelas que reúnem o corpo e as feições de uma pessoa com os de certo personagem. Os retratos apresentados aqui derivam, portanto, de uma tomada de posição em um sistema relacional que inclui o princípio de ver e ser visto, princípio esse potencializado em situações rituais como uma festa de grande repercussão local.

Isso posto, gostaria de apresentar nas linhas que seguem as condições de produção dessas fotografias e como sua existência explicita um tipo de mútuo engajamento produzido entre mim, a câmera e os sujeitos retratados. Ao longo da pesquisa, a utilização da tecnologia fotográfica assumiu funções variadas durante as estadas em campo, auxiliando continuamente na produção de conhecimento (Martins, 2009; Novaes, 2012 2). Diferentemente da experiência vivida durante os anos do mestrado, quando lidava com um grupo religioso caracterizado pela produção intencional e contínua de imagens de si mesmo - pela televisão ou pela internet (Pereira, 2008) -, no doutorado eu lidava com um tipo de ritual caracterizado pela simultaneidade de celebrações que se exprimia sob outra lógica expositiva e visual, na qual múltiplos agentes, materialidades e estímulos sensoriais se sobrepõem e conjugam do decorrer de um fato social total (Mauss, 2003). Assim, nos primeiros anos do estudo em Ouro Preto, realizei incursões munido de uma pequena câmera digital ${ }^{8}$ que me servia como produtora de registros e memória de cenas, pessoas e da aparência dos 
artefatos utilizados na Semana Santa. Tal uso do aparelho fotográfico se beneficiava do fato de que ele cabia no meu bolso, analogamente ao bloco de papel que eu mantinha quase sempre comigo. Ambos produziam dados a decodificar para dar subsídio à escrita etnográfica.

Com o avançar do tempo, porém, passei a interagir com fotógrafos moradores da cidade, que se dedicavam a documentar essa e outras festas locais. Em geral, as fotografias que eles faziam das mesmas cenas e personagens que me interessavam exprimiam um conjunto de qualidades estéticas que eu pouco dominava. Foi mediado por seu trabalho que ocorreu minha socialização em certo vocabulário técnico e na qual recebi os primeiros estímulos para experimentar novas formas de enquadramento dos sujeitos e cenas fotografadas. Eles me ensinaram, entre outras coisas, a observar não só o tema em destaque, mas o seu entorno, ajudando a "limpar" a cena - ainda que, em muitos casos, vários desses mesmos fotógrafos tivessem predileção em enquadrar certas pessoas em meio à festa ou em procissão. ${ }^{9}$

Essas relações colaboraram decisivamente na progressiva modificação do meu olhar mediado pela câmera fotográfica - que se tornou quase onipresente nos últimos anos da pesquisa. Motivado pelos conselhos desses interlocutores, no terceiro ano da pesquisa, retornei à cidade com uma câmera nova. Tratava-se de um aparelho maior e tecnicamente melhor que o anterior, que passava a ficar continuamente visível sobre o meu corpo. ${ }^{\text {I0 }}$ Confirmando certa expectativa, a segunda câmera ajudou a reforçar vínculos de sociabilidade e ampliou o número de imagens produzidas (ao fim da pesquisa acumulei mais de 4,5 mil arquivos). A introdução desse segundo aparelho foi acompanhada, não obstante, por uma alteração no modo como certos moradores me classificavam. Alguns, também entre os que já me conheciam, passavam a chamar-me de "fotógrafo" ou "jornalista", indicando que a câmera se tornava um artefato diacrítico em minha identificação pública (ou na imagem que construíam de mim).

Outra alteração decorrente da utilização da câmera maior, um fato particularmente importante para este ensaio, foi o aumento do número de figurados que, ao reconhecer minha presença próxima ao grupo, observando-os, passava a posar para fotos, sorrindo e encenando gestos próprios de seus personagens. Essas novas posturas corporais e sorrisos revelaram-se como sinal inequívoco de meu aprofundamento no jogo mútuo de reconhecimento visual produzido na e pela festa. Tornava-se claro que a lente da câmera não simplesmente registrava aquilo que acontecia diante dela e à minha revelia. Na verdade, o aparelho direcionado àquelas pessoas apresentava-se como um novo órgão perceptivo (Rouch, 2003: 98) que se interpunha e afetava as relações até então estabelecidas. A câmera e seu uso se associavam, assim, aos vários tipos de respostas dadas à ação nativa de se apresentar publicamente como a alteridade narrada na Bíblia. 
Através do feixe de luz que atravessa o corpo da máquina fotográfica, eu passei a ficar cada vez mais enveredado nas formas dessa armadilha estética incorporada pelas figuras bíblicas, personagens de uma forma própria de celebrar a Paixão cristã. Ao evocar a metáfora analítica da armadilha estética, inspiro-me na abordagem que Babadzan (I98I) e Gell (200I) fizeram sobre artefatos e imagens rituais, destacando o fato de que a configuração atual do grupo de performers - ou melhor, aquela aqui retratada e reproduzida - é o resultado de um conjunto de intencionalidades complementárias ou contraditórias que o produziram ao longo de sua biografia, indo desde a idealização até a concretização e os efeitos que produz. Assim, cada retrato do figurado bíblico revela mais do que a reunião do rosto/corpo de uma pessoa com a imagem inferida de sua figura. Exprime-se igualmente a conjugação de ambos, pessoa e personagem, com o trabalho prévio das organizadoras e das costureiras, a socialização anterior com familiares e amigos que já atuaram os papéis bíblicos, além do repertório religioso e da rivalidade paroquial acionada pela festa etc. Enquanto armadilha, o figurado pode ser compreendido como uma forma de objetificação de várias agências que se exprimem sob princípios estéticos em um dado espaço-tempo - aí incluídos os artefatos, as pessoas e seus corpos (Gell, I998). Cada figura como o resultado - temporário - de uma cadeia de relações que a antecede e engloba. Uma soma de elementos conjugados com o objetivo de capturar a atenção, os olhares, e mobilizar a emoção de seu público. Ou seja, fazendo das pessoas que os veem passar nas procissões, moradores e turistas, suas vítimas em potencial.

Dada a natureza da relação estabelecida com tais figuras e o adensamento de minha percepção analítica mediada pela fotografia, passei a apostar no cliché antropológico de seguir o "ponto de vista nativo" para orientar não só a escrita etnográfica, mas também a produção de retratos de meus interlocutores. Nos últimos anos, a estética nativa passou a desempenhar papel-chave no enquadramento da minha observação e produção fotoetnográfica. Assim, considerando que a expressão estética em foco se vale da tradição iconográfica cristã e de sua capacidade de condensar múltiplos sentidos em uma única imagem, baseei-me em um modelo de representação pictural para retratar o figurado bíblico. A estética nativa convertendo-se, afinal, em uma ferramenta heurística para sua apreensão visual.

Em termos gerais, a representação figural é uma modalidade de encenação teatral desprovida de movimento dramático que, no Ocidente, remete a uma tradição específica na forma de recontar histórias de santos católicos (Teulade, 20I2: 48). Nesse tipo de representação, assim como na sucessão de figuras que ocorre nas procissões ouro-pretanas, a mensagem é passada pela sobreposição de imagens ou cenas que possuem, cada qual, valor e sentido em si mesma. Os personagens apresentados não se engajam em uma única trama com início, meio e fim - como ocorre em inúmeros autos e filmes que recontam 
a Paixão de Cristo. A representação pictural caracteriza-se por sua composição rapsódica e não linear, de modo análogo à "cena" heteróclita com diferentes santos que pode ser composta no altar de um templo. Embora várias efígies e personagens estejam dispostos em um mesmo espaço, cada qual aponta para uma narrativa iconográfica e hagiográfica própria. Cada figura nos interpela à sua própria maneira, alguns nos atraindo por certo detalhe, outros nos desafiando a decifrar sua identidade a partir dos índices que ostentam.

Assim, a teatralidade e aparente fixidez das poses nos retratos aqui apresentados indica uma forma particular de exprimir a capacidade agentiva dessas figuras. Ao dar ênfase aos rostos, as fotografias permitem a dramatização de uma possível troca de olhares dos personagens retratados com os leitores, recriando, assim, um tipo de comunicação que pode ser acionada tanto entre devotos e imagens religiosas, quanto entre certas fotografias e os que se valem dessas imagens para tornar atual a memória ou presença dos retratados - como na experiência narrada por Barthes (I984: IOI): "Sozinho no apartamento em que ela há pouco tinha morrido, eu ia assim olhando sob a lâmpada, uma a uma, essas fotos de minha mãe, pouco a pouco remontando com ela o tempo, procurando a verdade da face que eu tinha amado. E a descobri."

A face, região sagrada do corpo humano e superfície visível da identidade, é onde se concentra o olhar que nos encara de volta ao ser mirado. Aprendi isso involuntariamente e desde criança, quando, ao visitar minha avó, tentava me desviar da vista de uma santa Terezinha que ficava pendurada na parede de seu quarto. Era uma imagem semelhante à que, tempos depois, reencontrei na casa de dona Maria em Ouro Preto. Na época de minha infância, os adultos se divertiam dizendo que ela acompanhava com os olhos aqueles que desobedecessem às ordens dos mais velhos. A figura impressa no papel nos vigiava. Uma mistura de medo e desconfiança marcava a iniciação de uma estranha familiaridade que me faria perceber que "as imagens pertencem à ordem das coisas vivas" (Samain, 20I2: I57), mesmo quando apresentam pessoas mortas ou personagens de algum passado.

Hoje, ao recuperar esse aprendizado, compreendo que o investimento antropológico com e sobre imagens, sobretudo em contextos rituais, precisa manter-se continuamente atento às intencionalidades humanas e não humanas que interpela, incorporando não só seus conteúdos à análise etnográfica, mas também suas formas de dar a ver e fazer viver certos personagens. 
652

Edilson Pereira é antropólogo, professor da ECO/UFRJ. Foi pesquisador de pós-doutorado na Universitat de Barcelona (2017-20I8). Sua tese de doutorado em antropologia social (Museu Nacional/UFRJ), sobre os personagens da Semana Santa e a produção ritual da memória em Ouro Preto (MG), recebeu o Prêmio Capes de Tese na área de antropologia e arqueologia (2015). Suas pesquisas e publicações abordam os temas da religião e das relações entre coisas, imagens e pessoas, incluindo performances e 'patrimônios' materiais e imateriais. 


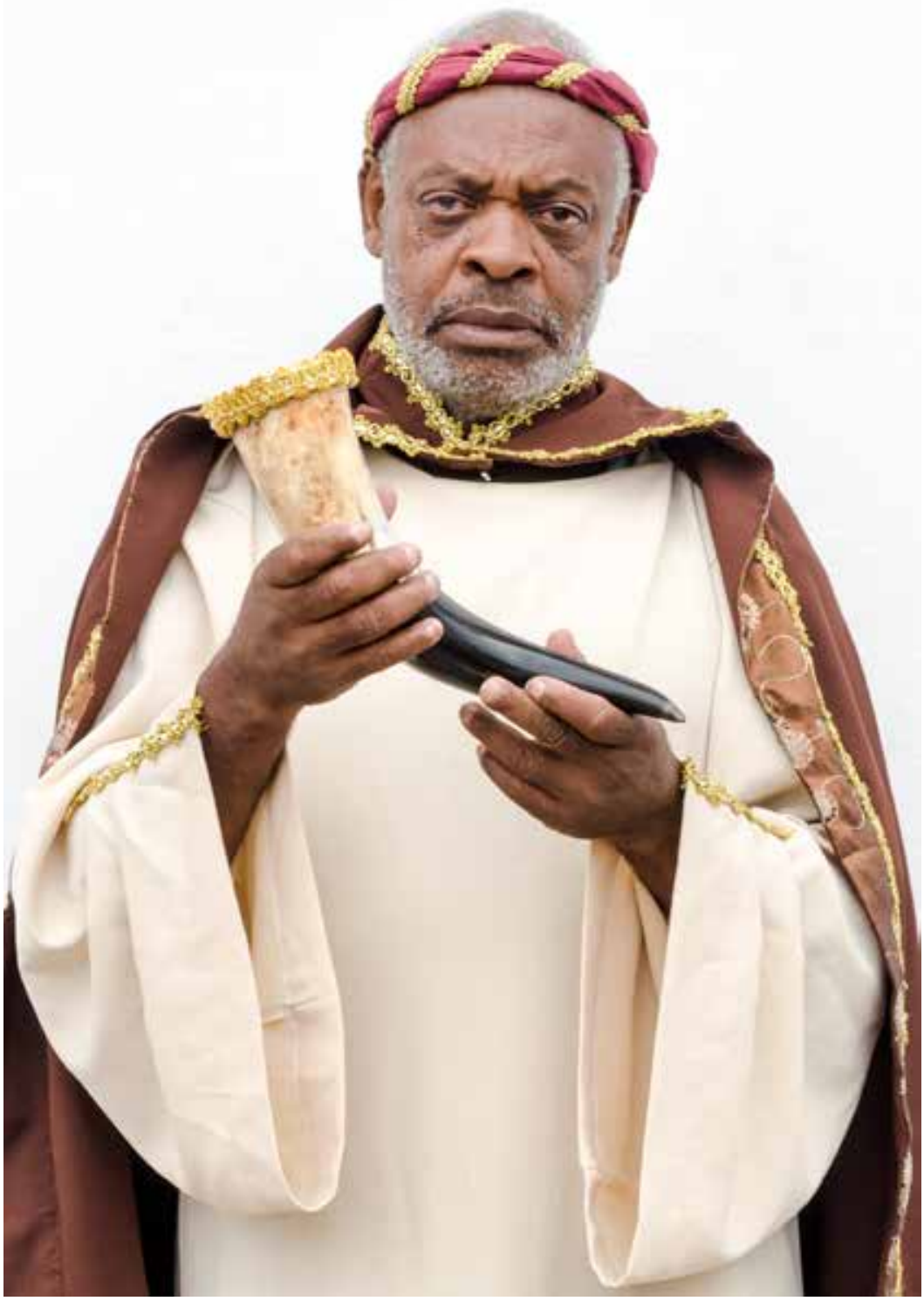

Série Figurados.

Roberto do Nascimento Ferreira como um dos reis do Antigo Testamento. Na Bíblia, o chifre aparece como metáfora de um reino político particular ou como uma ameaça aos crentes "Eu olhava e eis que este chifre fazia guerra contra os santos e prevalecia contra eles, até que veio o Ancião de Deus e fez justiça aos santos do Altíssimo" (Daniel 7: 2I-22)

Ouro Preto, 2015. Acervo do autor 


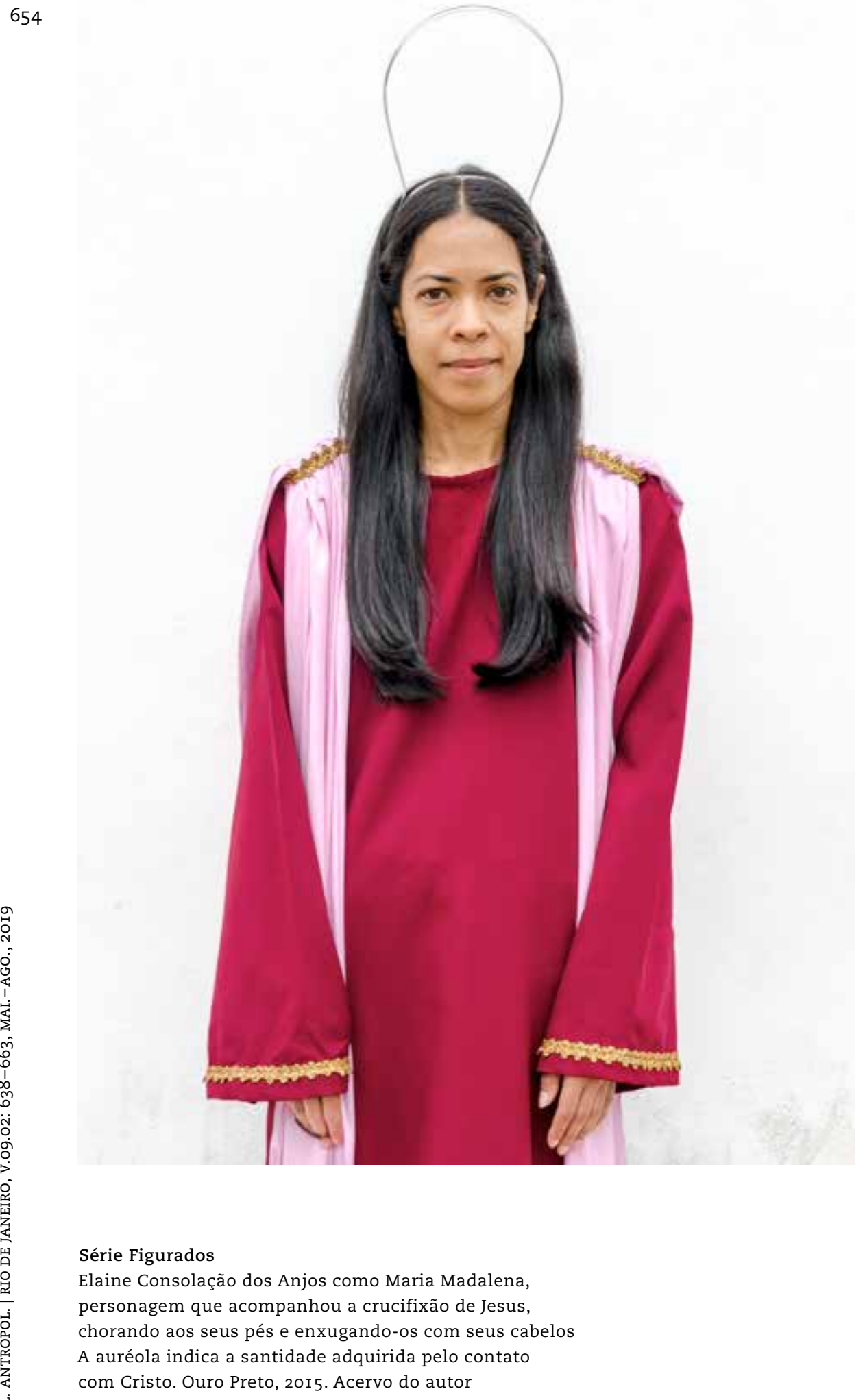




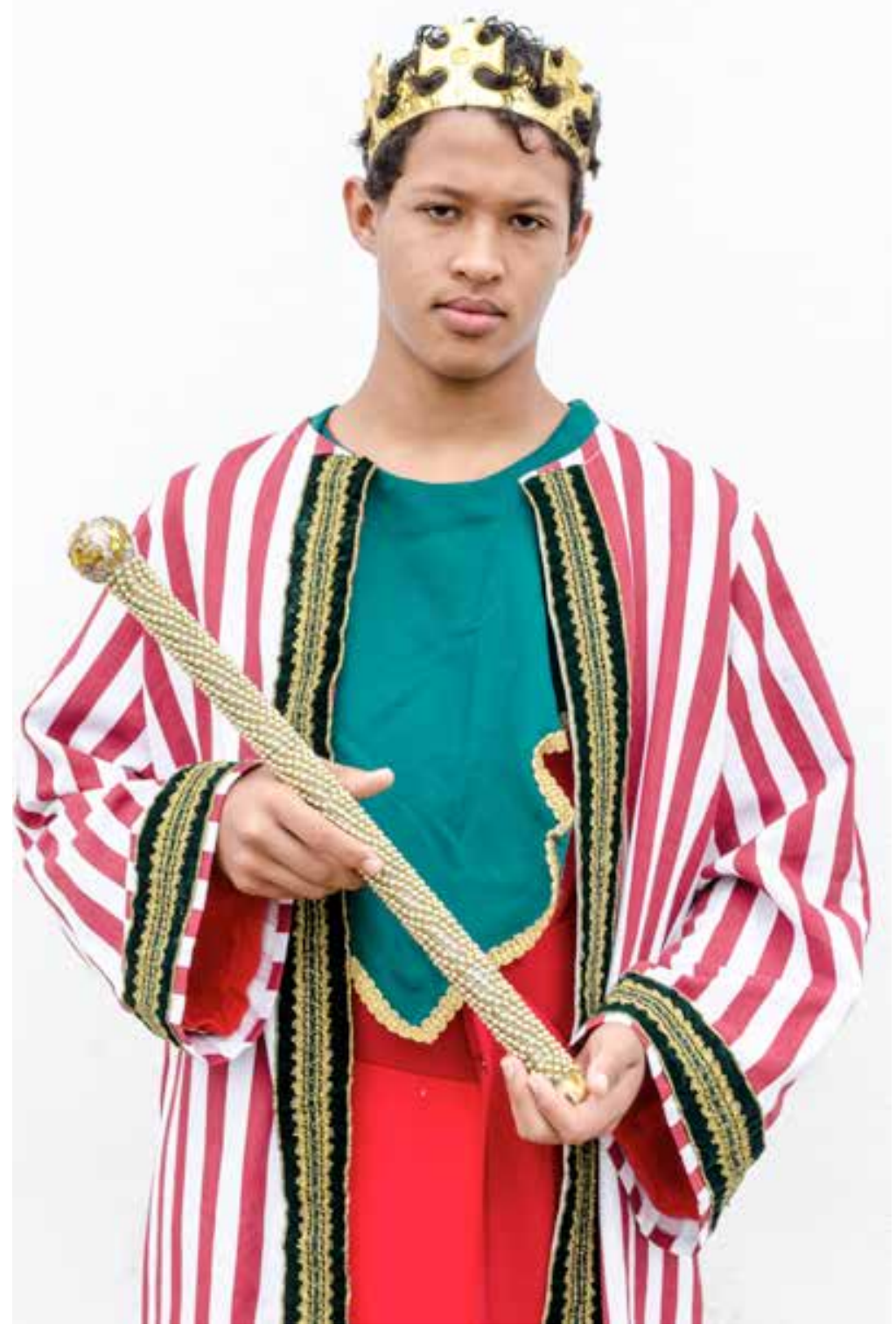

Série Figurados

Igor Cesar Barbosa de Figueiredo como rei Davi

Nos textos bíblicos, a referência ao cetro pode indicar

tanto realeza quanto justiça

Ouro Preto, 2015. Acervo do autor 


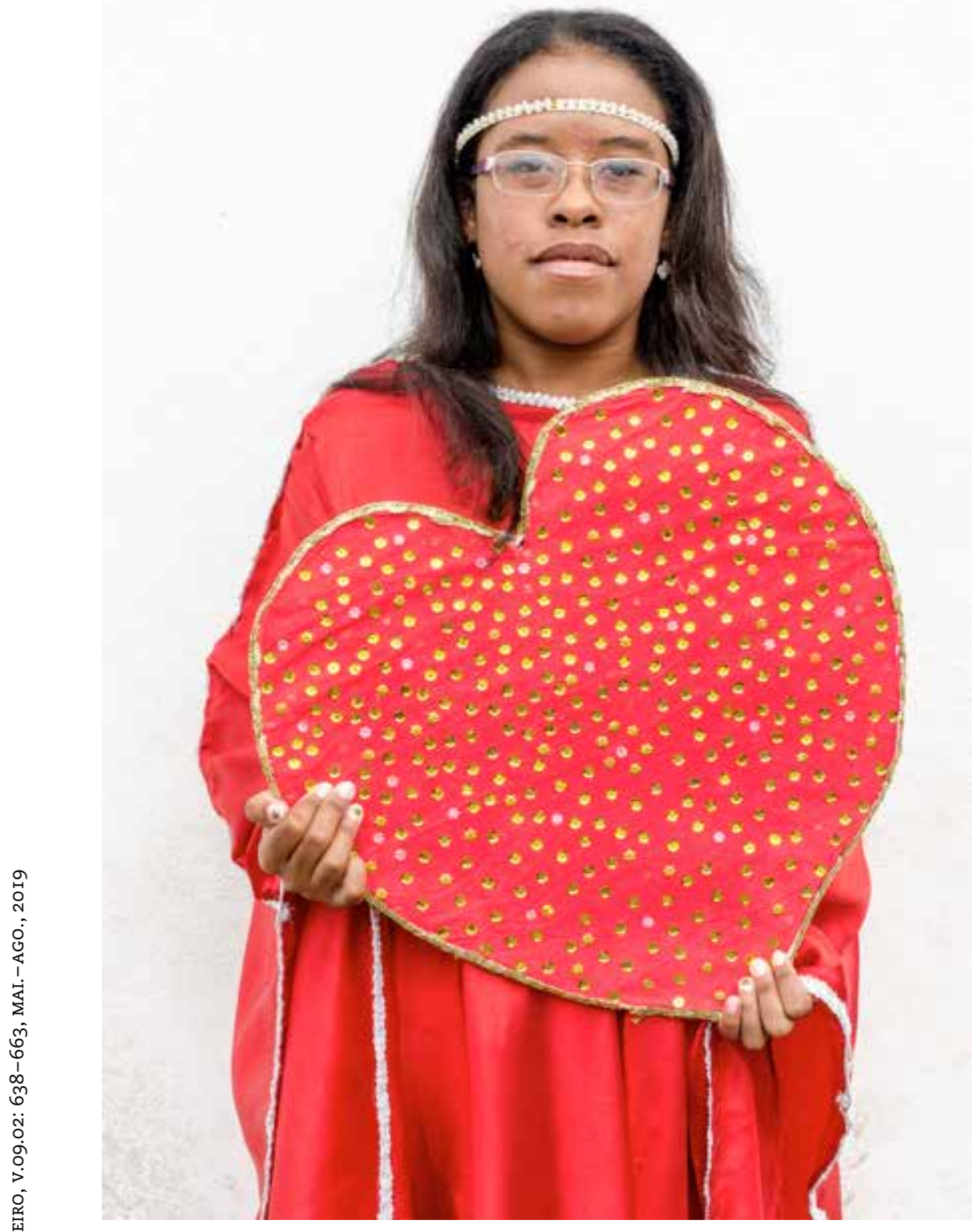

\section{Série Figurados}

Ana Emília Ferreira Oliveira como uma alegoria das Sete Virtudes (Humildade, Generosidade, Castidade, Paciência, Temperança,

Caridade e Diligência) que se opõem aos Sete Pecados Capitais

Ouro Preto, 2015. Acervo do autor 


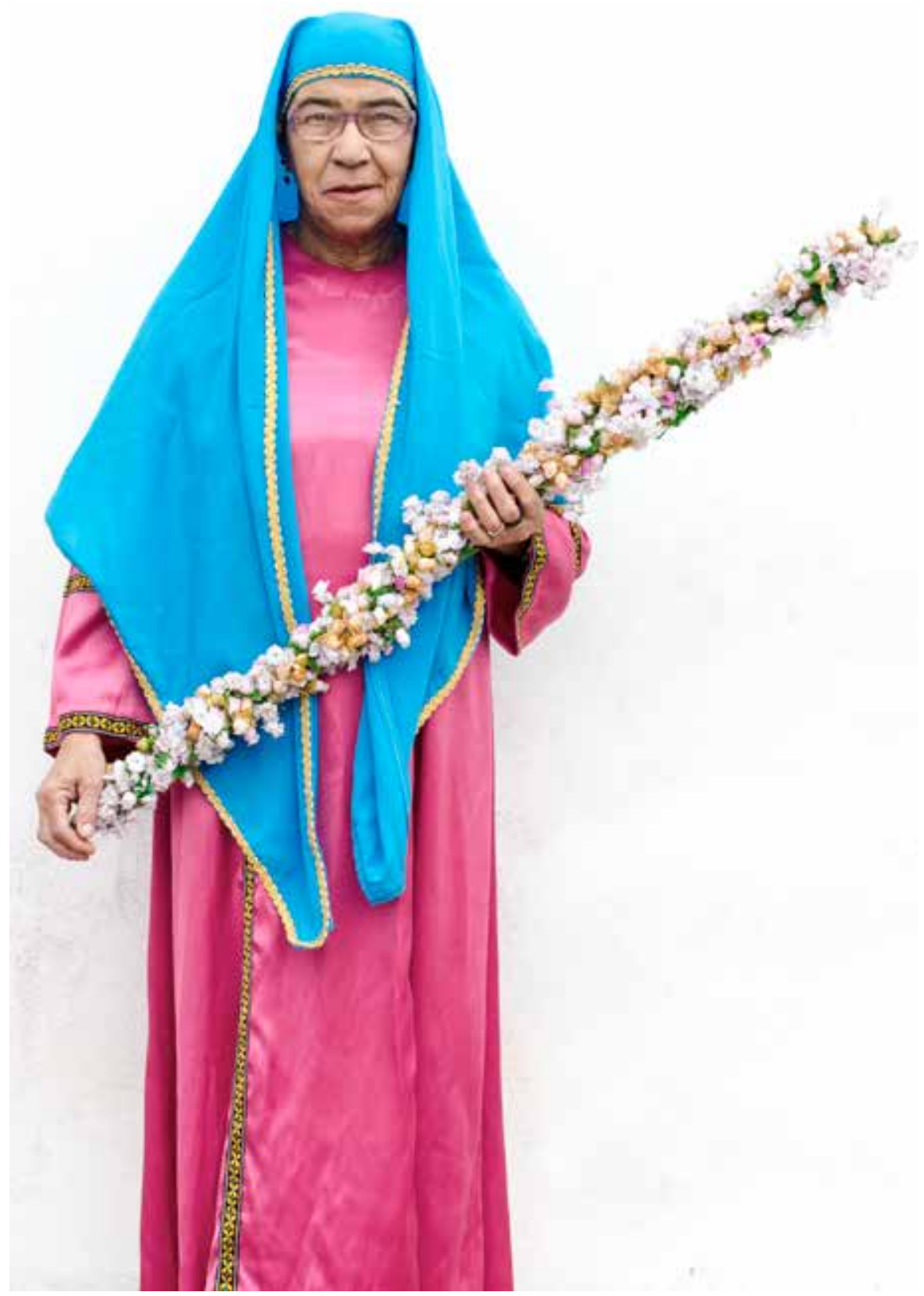

\section{Série Figurados}

Amarina Souza como Lia, a primeira esposa de Jacó e mãe de sete filhos. Desses, seis homens comandavam metade das 12 tribos que fundaram a antiga nação de Israel

"Lia tinha os olhos ternos" (Gênesis, 29: I7)

Ouro Preto, 2015. Acervo do autor 
658

\section{NOTAS}

I A santa é conhecida também como santa Terezinha do Menino Jesus e da Santa Face ou, ainda, como Teresa de Lisieux (I873-I897, França). Ela integrava a Ordem Primeira do Carmo, associação católica difundida em várias partes do mundo, incluindo o Brasil. Para mais detalhes, conf. Neves \& Cotta (2010).

2 Pesquisa realizada no âmbito do doutorado em antropologia, no Museu Nacional/UFRJ, sob orientação de Renata de Castro Menezes. A pesquisa (2009-20I4, com retorno em 20I5) foi realizada com o apoio do Grupo de Pesquisa em Antropologia da Devoção, GPAD.

3 Na história brasileira, a prática de vestir os mortos como figuras divinizadas, santos ou anjos, é interpretada pela literatura especializada como uma das heranças do catolicismo ibérico. No contexto colonial, e de catequização, os jesuítas "tudo fizeram para enfeitar ou embelezar a morte da criança" (Freyre, 2003: 203). "Vestindo a criança com as roupas deste ou daquele santo, os pais imaginavam garantir que seu rebento não ficaria desamparado no outro mundo", comenta um pesquisador do tema (Vailati, 2006: 6I). Em relação aos adultos, o vestir também auxiliaria na "salvação" do morto e na continuidade da sua unidade familiar (Reis, I985).

4 A fala, originalmente em francês, é reproduzida no site da Association Universelle des Amis de Jeanne d'Arc, disponível em http://www.amis-jeanne-darc.org/index. php? option $=$ com_content $\&$ view $=$ article $\&$ id $=8 \mathrm{I}$ : saintetherese-de-lisieux-et-sainte-jeanne-darc\&ca tid=48:religion-spiritualite\&Itemid $=72$. As fotografias de Terezinha no papel de Joana d'Arc, por sua vez, fazem parte do acervo dos Archives du Carmel de Lisieux, onde integram parte das "recreações piedosas", isto é, peças teatrais de temática religiosa, criadas ou encenadas por Thérèse durante seu tempo de clausura no convento. Disponível em http://www.archives-carmel-lisieux.fr. Agradeço a Emerson Giumbelli pela indicação dessa interessante referência.

5 Além disso, Thérèse de Lisieux era devota do Sudário, daí a menção à "Sagrada Face" em uma de suas invocações. Para mais detalhes sobre a atuação das Verônicas no in- 
terior do Brasil e em Ouro Preto, conf. Pereira (2015). Para mais detalhes sobre a história do vero ícone, e sua relação, moderna, com a fotografia, conf. Belting (2007).

6 A expressão citada foi utilizada em matéria publicada no jornal O Globo, no caderno Boa Viagem, em 25/2/2010 (disponível em <http://oglobo.globo.com/boa-viagem/semana-santa-paixao-de-cristo-moda-mineira-3048979>. Acesso em 25 nov. 2017.

7 O principal marco fronteiriço das paróquias é a praça Tiradentes. Segundo os moradores, as paróquias se revezariam na celebração da Semana Santa desde o século XVIII alternando a sede da festa entre os anos pares (20I4, 20I6, 2018...) no Pilar e os ímpares (2013, 2015, 2017...) no Antônio Dias. A prática atual resultaria de um antagonismo antigo, vinculado a conflitos que remontam à fundação da cidade e que teriam oposto os dois "lados" rivais cujos territórios, hoje, equivalem às paróquias citadas. A festa é o momento privilegiado de atualização dessa memória agonística que passa a ser expressa pelo cuidado es tético dos cortejos religiosos, sendo também entremeado por provocações jocosas entre paroquianos do "lado de cá" ou de "lá" da cidade.

8 Modelo: Nikon Coolpix P6o.

9 Alguns dos resultados desse investimento foram selecionados para compor o ensaio publicado em <https://revistas.pucsp.br/index.php/aurora/article/view/6265/5450>. Outras imagens, além dessas, foram selecionados também para a exposição coletiva realizada no $34^{\circ}$ Encontro Anual da Anpocs, em 20ıo, sob o título Tempo santo: uma festa em Ouro Preto. A participação nesses e em outros eventos acadêmicos foi marcada pela generosidade dos colegas pesquisadores e também influenciou a continuidade do interesse sobre a linguagem fotográfica e audiovisual em articulação com o conhecimento antropológico.

Io Modelo: Nikon D5000, lente 50mm. Parte dos registros realizados com essa câmera compuseram o ensaio "Anjos de Minas", que integrou a Mostra Pierre Verger de fotografias na $29^{\underline{a}}$ Reunião Brasileira de Antropologia, em Natal-RN, 2014. 


\section{REFERÊNCIAS BIBLIOGRÁFICAS}

Albers, Irene. (2008). Mimesis and alterity: Michel Leiris's ethnography and poetics of spirit possession. French Studies, 62/3, p. 271-289.

Babadzan, Alain. (I98I). Les dépouilles des dieux: essai sur la symbolique de certaines effigies polynésiennes. Anthropology and Aesthetics, I, p. 8-39.

Barthes, Roland. (I984). A câmara clara. Nota sobre a fotografia. Rio de Janeiro: Nova Fronteira.

Belting, Hans. (2007). La uraie image: croire aux images? Paris: Gallimard.

Campos, Adalgisa Arantes. (2005). Aspectos da Semana Santa através do estudo das Irmandades do Santíssimo Sacramento: cultura artística e solenidades (Minas Gerais séculos XVII ao XX). Barroco, I9, p. 7I-88.

Cavalcanti, Maria Laura Viveiros de Castro; Gonçalves, José Reginaldo dos Santos. (2010). Cultura, festas e patrimônios. In: Duarte, Luis Fernando Dias; Nunes, Carlos Benedito (orgs.). Horizontes das ciências sociais: antropologia. São Paulo: Anpocs/Editora Barcarola/ICH, p. 258-292.

Freyre, Gilberto. (2003). Casa-grande \& senzala: formação da família brasileira sob o regime da economia patriarcal. São Paulo: Global.

Gell, Alfred. (200I). A rede de Vogel: armadilhas como obras de arte e obras de arte como armadilhas. Arte \& Ensaios, Rio de Janeiro, 8/8, p. I74-I9I.

Gell, Alfred. (1998). Art and agency: an anthropological theory. Oxford: Clarendon Press, I998.

Gonçalves, Marco Antonio Teixeira. (2016). Retrato, pessoa e imagem: o universo fotográfico de Madalena Schwartz. Revista de Antropologia, 59/3, p. 239-264.

Jolles, André. (1976). A legenda. In: Formas Simples. São Paulo: Cultrix, p. 30-59.

Le Breton, David. (I995). Le visage et le sacré: quelques jalons d'analyse. Religiologiques, I2, p. 49-64.

Leiris, Michel. (20I7). O sagrado na vida cotidiana. Debates do NER, ano I8/3I, p. I5-25.

Leiris, Michel. (I989). La possession et ses aspects théâtraux chez les Éthiopiens de Gondar. Paris: Fata Morgana. 
Lima, Raquel dos Santos Sousa. (2006). "Oh! Que imitem a Santa Rita de Cássia!” as mulheres de nosso tempo: representações e práticas da devoção em Viçosa, 2003-2006. Dissertação de Mestrado. PPGH/Universidade Federal Fluminense. MacDougall, David. (2006). The corporeal image: film, ethnography and the senses. Princeton/Oxford: Princeton University Press.

Martins, José de Souza. (2009). Sociologia da fotografia e da imagem. São Paulo: Contexto.

Mauss, Marcel. (2003). Sociologia e antropologia. São Paulo: Cosac \& Naify.

Menezes, Renata de Castro. (20II). A imagem sagrada na era da reprodutibilidade técnica: sobre santinhos. Horizontes Antropológicos, I7/36, p. 43-65.

Neves, Maria Agripina; Cotta, Augusta de Castro. (2010). Do Monte Carmelo a Vila Rica: aspectos históricos da Ordem Terceira e da Igreja do Carmo de Ouro Preto. Ouro Preto: edição do autor.

Novaes, Sylvia Caiuby. (20I2). A construção de imagens na pesquisa de campo em Antropologia. Iluminuras, I3/3I, p. II-29.

Pereira, Edilson. (2017). The bodies of Christ: performances and agencies of Passion in Ouro Preto. Vibrant: Virtual Brasilian Anthropology, I4/I.

Pereira, Edilson. (20I6). O santo, a face e o outro: quando Cristo e Tiradentes se encontram em Ouro Preto. Etnográfica, 20/2, p. 363-386.

Pereira, Edilson. (2015). As mulheres por trás da face de Cristo: apropriações, performances e ambivalências da Verônica. Religião \& Sociedade, 35/I, p. I93-2I5.

Pereira, Edilson. (2014). O teatro da religião: a Semana Santa em Ouro Preto vista através de seus personagens. Tese de Doutorado. PPGAS/Universidade Federal do Rio de Janeiro.

Pereira, Edilson. (2008). O espírito da comunidade: passagens entre o mundo e o sagrado na Canção Nova. Dissertação de Mestrado. PPGSA/Universidade Federal do Rio de Janeiro. Pinney, Christopher. (1992). The parallel histories of Anthropology and Photography. In: Edwards, Elizabeth (ed.). Anthropology \& Photography I860-I920. New Haven/London: Yale University Press, p. 74-95. 
Reis, João José. (1985). A morte é uma festa. São Paulo: Brasiliense.

Rouch, Jean. (2003). On the vicissitudes of the self: the possessed dancer, the magician, the sorcerer, the filmmaker and the ethnographer. In: Ciné-Ethnography. Minneapolis: University of Minnesota Press, p. 87-Ior.

Samain, Etienne. (2012). As peles da fotografia: fenômeno, memória/arquivo, desejo. Visualidades, Io/I, p. I5I-I64.

Simmel, Georg. (I986). Digresión sobre sociología de los sentidos. In: Sociología. Estudio sobre las formas de socialización, t. 2. Madrid: Alianza, p. 676-695.

Soutto Mayor, Sarah Teixeira. (2012). O carnaval de Ouro Preto: mercado e tradição (I980-20II). Dissertação de Mestrado em Lazer. Universidade Federal de Minas Gerais.

Teulade, Anne. (2012). Le saint mis en scène. Paris: Les Éditions du Cerf.

Vailati, Luiz Lima. (2006). As fotografias de "anjos" no Brasil do século XIX. Anais do Museu Paulista: História e Cultura Material, I4/2, 5I-7I. 
Palavras-chave

Personagem ritual; fotografia; antropologia visual;

Ouro Preto; Semana Santa.

Keywords

Ritual character; photography; visual anthropology;

Ouro Preto; Holy Week.

\section{AS IMAGENS ENCARNADAS ENTRE MORTOS E VIVOS: NOTAS ETNOGRÁFICAS SOBRE RITUAL E RETRATO}

\section{Resumo}

O texto aborda a prática ritual do vestir-se como uma figura da tradição cristã. Com base em pesquisa realizada sobre a celebração da Semana Santa em Ouro Preto, MG, descrevo as referências iconográficas e os parâmetros que orientam a performance do "figurado bíblico" na cidade - um grupo efêmero de moradores que participam das procissões da época vestindo-se como personagens do Antigo e do Novo Testamento. Coloco em questão o uso da fotografia como parte do investimento etnográfico sobre atividades rituais que se valem da aparência e fisicalidade humanas para representar e atualizar imagens religiosas. Junto ao texto, apresento uma série de retratos cuja produção buscou levar em consideração as formas de expressão e dramatização nativas para orientar sua linguagem estética.

\section{EMBODIED IMAGES BETWEEN THE DEAD AND} THE LIVING: ETHNOGRAPHIC NOTES ON RITUAL AND PORTRAITURE

\section{Abstract}

The paper discusses the ritual practice of dressing up as a figure from the Christian tradition. Based on ethnographic research on the celebration of Holy Week in Ouro Preto, Minas Gerais, it describes the iconographical references and parameters that guide the performance of the "biblical figure" in the city - an ephemeral assembly of local residents who participate in the Catholic processions dressed as characters from the Old and New Testaments. It also calls into question the use of photography by an anthropological study of ritual activities that make use of human appearance and physicality to represent and actualize religious images. It includes a portrait series whose production takes into account native forms of expression and dramatization to inform its aesthetic language. 